\title{
Cognitive Framework Underlying Learning Strategies for Academic Speaking
}

\section{Lulus Irawati}

This article aims to discuss about cognitive framework underlying learning strategies for acadeic speaking. Cognitive framework underlies learning strategies, since there are four stages of encoding process that cover not only the way store things to be learnt but also the way people organize way store things to be learnt but also the way people organize. Moreover, the learning strategies are helpful for motivating the students to be active and creative in order to develop their communicative competence. In the learning strategies, the students are encouraged to participate actively in real communication. Hopefully, this article can give contribution to the teacher and lecturer in teaching speaking skill

\section{Introduction}

Chomsky had absolutely contributed a great idea on second language acquisition when he postulated 'language is a mental fact'. Certainly, it refers to human knowledge to acquire the language existing inside his/her brain that psychologically is the so-called cognition. Within second language acquisition, connection between language and cognition can be extremely understood. As everybody knows, language is acquired unconsciously reflecting that it is cognitive process. In cognitive psychology, there are four stages of encoding process to acquire new information, namely selection, acquisition, construction and integration. In selection, learners choose specific information from their surrounding and then store the information into working memory. At the second stage, acquisition, the learners start to transfer the information from working memory into long-term memory. Then, the learners actively connect ideas and create schemata into which the new ideas can be organized. Finally, anytime the learners want to activate prior knowledge, they can search it in long-term memory and transfer it to working memory (Weinstein and Meyer in O'Malley and Chamot, 1990). Further, the process incorporates how much is learned, what is learned and how it is organized. That is, learning strategies are obviously needed in second language acquisition to promote the learner's awareness during early stages of learning. Learning strategies can be defined as strategies to support learning by actively engaging person's mental process. Ideally, the more repeated those strategies are used, the more successful learning will be. To sum up, cognitive framework underlies learning strategies, since there are four stages of encoding process that cover not only the way store things to be learnt but also the way people organize. 
In addition, Chomsky's theory, cognitive framework, and their connections to the application of learning strategies are going to be elaborated in the following.

\section{Chomsky's theory and its connection with cognitive framework}

Chomsky is one of the greatest linguists for many decades ago postulating two fundamental distinction between competence--human's knowledge of his/her language and performance--the use of language in real situation (Chomsky, 1965). Competence is extremely connected with a mental or psychological fact that every language speaker can only create sentences or expression, if there is complete grammar system inside his brain. Then hopefully, it can reflect into speaker's language performance. Chomsky concerns best on linguistic competence, which is the so-called generative grammar - a grammar of language based on speaker-hearer's intrinsic competence (Chomsky, 1965). Thus far, generative grammar particularly specified on the level of syntax with the formulation of generative rules which show explicitly things hidden in the mind.

Furthermore, there are two basic assumptions taken from generative grammar namely 'human language is fundamentally creative' and 'language is a mental fact' (Effendi Kadarisman, 2010).
First, human language is fundamentally creative, since human tends to create creatively different words or expressions during communicating with others daily. For instance, today, I produce the word 'love is friendship' as a response of discussing to match two of my S3 classmates to be a couple and the other day, I probably create other new sentences from different topics. It clearly shows that the human creativity in language use can be different and unpredictable day by day. It flows automatically as a response of interacting or communicating with others. The second assumption is that language is a mental fact. Language is something biologically considered inside the brain that reflects into the so-called linguistic competence. Thus, it can certainly respond questioning on how children acquire the competence that there is a gifted device inside of children's brain and make them automatically understand and create sentences or utterances. For example, when children at early age mumbled papapapa, mamama, dadada that at first those words were difficult to be understood by people around and later those sound became meaningful to be papa, mama, kakak, etc. Then, Chomsky proposes the device called LAD (language acquisition device) hypothesis - a device enabling children to acquire language and much like a linguistic blueprint (Effendi 
Kadarisman, 2010). Since all human languages are particularly the same in term of acquisition, the LAD produces the socalled Universal Grammar (UG) that provides system, rules or properties of language universally. Finally yet importantly, human language is innate which has been there inside human's brain as a gift of God.

In line with the theory stated above, it shows that Chomsky's ideas entirely present human competence in learning a language endowed at birth that has been there inside human's brain. Clearly, it is part of cognitive psychology. The cognitive framework greatly contributes to language acquisition and learning although Chomsky had never stated whether his theories were contributing to them or not. In fact, cognitive framework influences many perspectives and ideas in language learning or acquisition, namely strategies, techniques, and many more. One of strategies strongly influenced is learning strategies. Those are going to be elaborated further in the next session.

\section{Learning Strategies for Academic Speaking}

In education perspective, learning means a conscious process in getting knowledge that is superficially difficult to be measured. There should be a thing to measure students' success in learning. That is, it is a strategy. Strategy can be a tool involving plan and management to achieve the success. Then, learning strategies are steps taken by the students to enhance their own learning and with appropriate learning strategies result in improved proficiency and greater self-confidence (Oxford, 1990). Moreover, the learning strategies are helpful for motivating the students to be active and creative in order to develop their communicative competence. In the learning strategies, the students are encouraged to participate actively in real communication. For instance, the students take benefit from using metacognitive strategies in a way of planning, focusing, and evaluating their progress toward communicative competence. Thus, the learning strategies can be applied not only under teacher guidance but also individually, since activating self-direction is the most important one in language learning.

In general, many typologies of strategies are developed and recommended by some researchers for research purposes. They are Rubin's typology, Oxford's typology, Cohen typology and Arend's typology. Here, I prefer Oxford's typology, for the components of learning strategies are more specific and comprehensive to support English for foreign language (EFL) easily. Further, 
Oxford divides the learning strategies into two major classes: direct and indirect strategies (Oxford, 1990). Direct strategies-involving the target language are divided into three strategies, namely memory strategies, cognitive strategies, and compensation strategies. Those part of strategies require mental processing of the language. Inside those strategies, there are still division of specific strategies that can be seen and applied directly in EFL classes, such as creating mental linkages, applying images and sounds, practicing, receiving and sending messages, guessing intelligently in listening or reading, and overcoming limitations in speaking, etc. Meanwhile, indirect strategiesunderpinning the business of language learning are divided into three strategies, namely metacognitive strategies, affective strategies, and social strategies. Those strategies have more specific and applicable division of strategies, such as evaluating your learning, lowering your anxiety, cooperating with others, etc. To sum up, the strategies above are useful to be applied entirely in four language skills: listening, speaking, reading, and writing.

Specifically, the selection of strategies is very individualistic. The students are often unconscious that the way they overcome their language learning problems refers to one of learning strategies. It clearly can be found out by distributing a set of questionnaire, the socalled SILL (Strategy Inventory for Language Learning) version 7.0 created by Oxford (1989). Further, I as a lecturer can use some key behaviors inside SILL when I would like to train or upgrade my students' learning strategies. For example, I may provide some pictures or information from multimedia, since ' $I$ connect the sound of a new English word and an image or picture of the word to help me remember' is one of key behaviors inside the SILL. In fact, the students can endorse themselves to use learning strategies without any teacher's guidance. Therefore, to collect the data on the use of learning strategies I modified SILL for speaking purpose only in 2007, since I investigated 'learning strategies used by different gender in speaking'. Here, I am going to use the modified SILL again for academic speaking, in this English Debate class, year 2011, IKIP PGRI Madiun. For this mini investigation, I become a passive observer and focus to explain the use of learning strategies viewed from one student's perspective only.

In line with the previous explanation, I start to elaborate the result of my mini observation, investigation and interview about the use of learning strategies for academic speaking. I divide my explanation into two parts: to elaborate the activities inside the classroom and to 
overview the use of learning strategies based on SILL. First, the English Debate lecturer explained in detail the debate material consisting of the technical terms: Australian, British, and Asian parliamentary, motions, case argument, evidence, rebuttal, speaker's role, adjudicating, affirmative team, negative team, etc. At that time, the students' responses were not good enough, since they were not familiar with the terms in debate. They did not have any ideas concretely how to conduct a debate. Then, the lecturer played the video of real debate competition showing that six people argued one another to defend their opinions under the motion 'THBT the high standard of national eaxamination is the cause of violation'. The video showed how to convince other people (affirmative team againts negative team or vise versa) on what they think with valid and reliable evidence. Right after that, the lecturer trained to make a good argument based on a certain motion. Based on the interview with the lecturer, he trained the students to make approximately one until five sentences of argument in order to support them to have critical thinking (personally interviewed with Bapak AR). He had done this treatment in about three meetings before they did the real debate that made them divide into groups of three people. In sum, there are many activities done to make the students activate their learning strategies either individually or under lecturer's guidance.

Moreover, to see what strategies are mostly used by the students, it is necessary to check the SILL result. SILL consists of 38 statements representing kinds of learning strategies with the score ranging from one to five. The highest score is five meaning 'always true' and the lowest score is one meaning 'never or almost never true'. Since there is only one student investigated here, the result of SILL and interview discussed is also based on her answer. Her named in abbreviation is RD. She is one of the students who actively participates in English Debate class and willing to be asked and share information. Based on the SILL, RD used the learning strategies almost in balance with overall average score, 4.2 meaning 'usually used'. Simultaneously, she used memory, cognitive, compesantion, metacognitive, affective and social strategies. Again, among strategies, compensation strategies have the highest score, 4.6 meaning that she often made guesses to understand unfamiliar words, used gestures during not finding word in conversation, made up new words if she did not know the right ones in English, and used words or phrases with similar meaning if she could not think an English word. Besides, she also confessed that she 
made notes and tried to memorize anytime she had to speak up in front the class, especially in English Debate class in which it is memory strategies. Viewed from the facts, the learning strategies have been used by the students unconsciously and perharps, the result can not be optimal. Therefore, it would be better if every lecturer provides some activities and materials to support the use of learning strategies, since it is very obvious that learning strategies can promote students' success in learning a language.

\section{Conclusion}

Chomsky perhaps had never clearly stated that his theory, Universal Grammar (UG) with his belief of LAD inside human as a birth endowment inspired other scholars to connect with another field, cognitive framework. Psychologically, cognitive framework has promoted to underly the success of students in learning a language, especially foreign language, English. In addition, the cognitive framework underlies learning strategies - a set of behavior needed to be measured in order to support the students' success in learning a language. Then, the lecturer or teacher needs to make the students get accustomed to using learning strategies by providing certain materials. After having regular practice, they may automatically use the learning strategies whenever they speak up in English either inside the classroom or outside the classroom. Further, cognitive framework has been successful to show the connection that learning strategies truly happen not in short time or instant, since it is related with human cognition. At last, my opinion, for future paper, it is necessary to incorporate linguistic field, in this case cognitive framework with teaching field in the form of approach or technique, such as CALLA (Cognitive Academic Language Learning Approach) and SBI (Strategies Based Instruction).

\section{References}

Chomsky, Noam. 1965. Aspects of the Theory of Syntax. Cambridge, Massachusetts: The MIT Press.

Kadarisman, A. Effendi. 2010. Mengurai Bahasa Menyibak Budaya: Bunga Rampai Linguistik, Puitika, dan Pengajaran Bahasa. Malang: UIN Press

O'Malley, J. Michael and Chamot, Ann Uhl. 1990. Learning Strategies in Second Language Acquisition. Cambridge: Cambridge University Press.

Oxford, Rebbeca L. 1990. Language Learning Strategies: What Every Teacher Should Know. Boston, Massachusetts: Heinle and Heinle Publisher. 